\title{
Fe-Based Amorphous Composite Coating Prepared by Plasma Remelting
}

\author{
Zhisheng Li, Zongde Liu, Yongtian Wang, Shunv Liu, Runsen Jiang, and Yang Wang
}

Key Laboratory of Condition Monitoring and Control for Power Plant Equipment of Ministry of Education, North China Electric Power University, Beijing 102206, China

Correspondence should be addressed to Zongde Liu; lzd@ncepu.edu.cn

Received 29 October 2014; Revised 16 January 2015; Accepted 6 February 2015

Academic Editor: Zoe Barber

Copyright (c) 2015 Zhisheng Li et al. This is an open access article distributed under the Creative Commons Attribution License, which permits unrestricted use, distribution, and reproduction in any medium, provided the original work is properly cited.

Fe-based amorphous composite coating was deposited on the carbon steel substrate by arc spraying and then remelted by a plasma remelting system, in order to improve the mechanical properties of the coatings. The composition, microstructure, and properties of the composite coating were analyzed by means of the metallographic microscope, scanning electron microscopy (SEM), energy dispersive spectroscopy (EDS), X-ray diffraction (XRD), and microhardness tester. The results showed that the amorphous composite coatings had more homogeneous and finer microstructure after the plasma remelting. The coating is metallurgically bonded with the substrate, and the hardness of the Fe-based amorphous composite coating is up to $1220 \mathrm{HV}$. The internal relationship between microhardness and microstructure has been discussed.

\section{Introduction}

Owing to the excellent wear/corrosion resistance and high hardness, the Fe-based amorphous composite coatings prepared by the arc spraying technique have attracted huge interest in surface technology area $[1,2]$. However, the arc spraying coatings have two considerable drawbacks: the high porosity and poor bonding strength with the substrate [3-6], which seriously deteriorate the performance of the coatings under the particle erosion wear and corrosion conditions. In this work, we perform a detailed investigation about the effect of the remelting plasma power on the properties of Fe-based amorphous composite coating. The coatings were firstly fabricated by the arc spraying and then remelted by plasma with optimal parameters. Both the microstructure and microhardness of the coatings were studied and compared.

\section{Materials and Methods}

Taking account of the common metal used in the coal-fired power plant's water wall tube, the $20 \mathrm{G}$ steel was selected to be the substrate material. The commercial QG1200 cored wire with $\Phi 2.0 \mathrm{~mm}$ was chosen as the arc spraying wire, which is a brand of spray wire. The nominal composition is as follows: $\mathrm{CrB}_{2}: 70 \%, \mathrm{Cr}_{2} \mathrm{C}_{3}: 30 \%$, rare earth: $0.5 \%$, and so forth. Mixed the powder uniformly, and wrapped with $0 \mathrm{Cr} 18 \mathrm{Ni} 9$ austenitic stainless steel, and drawn into a cored wire, and the powder accounted for $30 \%$. The thermal spraying experiment was conducted using BP-400 type arc spraying equipment manufactured by Praxair-TAFA Company and the remelting equipment using type of Ultima-150 manufactured by Victor Technology Company.

The size of the $20 \mathrm{G}$ steel plate is $200 \mathrm{~mm} \times 200 \mathrm{~mm} \times$ $10 \mathrm{~mm}$. Prior to coating, the substrate was blasted with 36mesh aluminum oxide to remove the oil and rust. The electric arc spraying apparatus and plasma remelting system were employed for the coating preparation. Both the arc spraying and plasma remelting experimental parameters are shown in Tables 1 and 2 . The thickness of the obtained coating is about $1 \mathrm{~mm}$.

The surface of the composite coatings was prepared using standard mechanical polishing procedures and etched by an alcohol nitrate solution. The microstructures were observed by scanning electron microscopy (SEM) equipped with an energy dispersive spectroscopy (EDS) detector. The 
TABLE 1: Arc spraying parameters.

\begin{tabular}{lccccc}
\hline No-load voltage & Working current & Air pressure & Spraying distance & $\begin{array}{c}\text { Spraying gun } \\
\text { traveling speed }\end{array}$ & Coating thickness \\
\hline $36 \mathrm{~V}$ & $260 \mathrm{~A}$ & $0.6 \mathrm{MPa}$ & $100 \sim 150 \mathrm{~mm}$ & $5 \sim 8 \mathrm{~cm} / \mathrm{s}$ & $1 \mathrm{~mm}$ \\
\hline
\end{tabular}

TABLE 2: Plasma remelting parameters.

\begin{tabular}{lcccc}
\hline Current & Plasma gas flow & $\begin{array}{c}\text { Protective gas } \\
\text { flow }\end{array}$ & Scanning speed & Nozzle distance \\
\hline $40 \mathrm{~A}$ & $1 \mathrm{~L} / \mathrm{min}$ & $3 \mathrm{~L} / \mathrm{min}$ & $3.5 \mathrm{~mm} / \mathrm{s}$ & $5 \mathrm{~mm}$ \\
\hline
\end{tabular}

crystallization behaviors of composite coatings were studied by the differential scanning calorimetry (DSC). The phases were analyzed by X-ray diffraction (XRD) meter with $\mathrm{Cu} \mathrm{K} \alpha$ $(\lambda=1.54178 \AA)$ radiation. The cross section microhardness was measured by the DMH-2 LS microhardness meter under a load of $300 \mathrm{~g}$, employing a loading time of $15 \mathrm{~s}$.

\section{Results and Discussion}

Figures 1(a) and 1(b) show the OM and SEM images of the cross-sectional regions of the coating deposited by arc spraying, respectively. During the process of spraying, the spraying wire was heated to the semimolten state or molten state, then blown to the substrate surface, flattened, and rapidly solidified, finally forming the layered structure morphology. The particles with mostly oval shape or flat shape are staggered, waved, and piled on each other. Therefore, the porosity of the arc spraying coating is high, even up to 5\% [7]. After the process of collisions between the molten drop and substrate, the irregular stacking causes the uneven overlap rate. The gas solubility in molten particles is reduced, and the solidification time of $10^{-7} \sim 10^{-6} \mathrm{~s}$ is too fast for the gas to spread out from the molten drops, resulting in the high porosity $[7,8]$.

In addition, a layer of particles which are not fully melted can be found in the interface of substrate and coating, and the reasons are speculated as follows: on the one hand, when reaching the surface of the substrate, the temperature of particles decreased dramatically, resulting in the fact that the particles in the interface experienced higher cooling rate; on the other hand, the substrate was not fully preheated at the beginning of the spray process, so these particles that firstly reached the substrate cannot fully deform. Those two reasons may cause the mosaic mechanical combination between the coating and the substrate.

Figure 2 presents the X-ray diffraction pattern of the coating after the plasma remelting. The XRD pattern shows a broad maximum peak around $45^{\circ}$ followed by a lesser intensity broad peak indicating that there exists the amorphous phase, and some broadened crystalline peaks were superimposed on the XRD curve due to the formation of nanocrystalline and amorphous matrix. In the vicinity of $45^{\circ}$ and $65^{\circ}$ weaker intensity appeared corresponding to the amorphous phase diffuse scattering package and superimposing a clear broadening of diffraction peaks. After calibrating the diffraction peaks, confirm that they are $\alpha$-(Fe, $\mathrm{Cr}$ ) and $\mathrm{Fe}_{2} \mathrm{~B}$ and $\mathrm{Cr}_{3} \mathrm{C}_{2}$. Using the Pseudo-Voigt function to fit the XRD diffraction [9], calculate the amorphous and nanocrystalline phase in the coating content; amorphous phase volume ratio is $41.42 \%$, and the nanocrystalline phase volume ratio is $34.37 \%$.

In order to confirm the presence of amorphous phase, DSC analysis was conducted and the results are shown in Figure 3. In the range $492.2^{\circ} \mathrm{C} \sim 569.1^{\circ} \mathrm{C}$ the coating has an exothermic peak crystallization temperature range, and in the vicinity of $511.2^{\circ} \mathrm{C}$ transition from the amorphous to the crystalline state occurs, and these variations illustrate that the coating contains amorphous phases. While at about $492.2^{\circ} \mathrm{C}$ amorphous phases in the coating began crystal transformation and at $511.2^{\circ} \mathrm{C}$ the curve reached its lowest point, the crystal changing occurred rapidly, and the dramatic changing in the curve was at $569.1^{\circ} \mathrm{C}$, indicating the occurrence of a phase transition.

Figure 4 shows the morphology of the transverse section of the arc spraying coating after the plasma remelting. Figure 4(a) shows the image of remelted zone, heat affected zone, and substrate material zone. After the plasma remelting, the layered structure of the coating disappeared, and the voids and unmelted particles produced in the arc spraying process were reduced. After melting, the microstructure is obviously refined and uniformly. Figures 4(b) and 4(c) show the images of the surface and center areas of the coating, and the sizes of grains near the surface of the remelted area are smaller than those in the center area and near the substrate interface. Figure 4(d) displays the SEM image of the cross section of the remelted area. It can be seen that, at the interface of the remelted area and the substrate, the direction of dendritic grains is vertical to the liquid-solid interface, which is in accordance with the heat flow direction. Figures $4(e)$ and 4(f) show the nanocrystalline/amorphous and the dispersion distribution of the ceramic particles of boride and carbide phase in the coating.

According to Figure 4, in the remelting process, the rodshaped particles overlap accumulation, and the amorphous phase sufficiently filled in the pores of the coating, the combined effect of these properties improve the compactness of the coating. In addition, the mutual pinning effect between dendrite area and intergranular eutectic area grid was aided by the dense amorphous filler, resulting in high hardness and impact resistance [10]. 


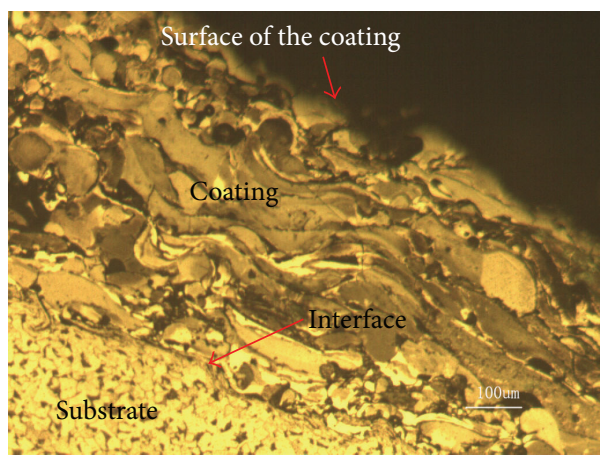

(a)

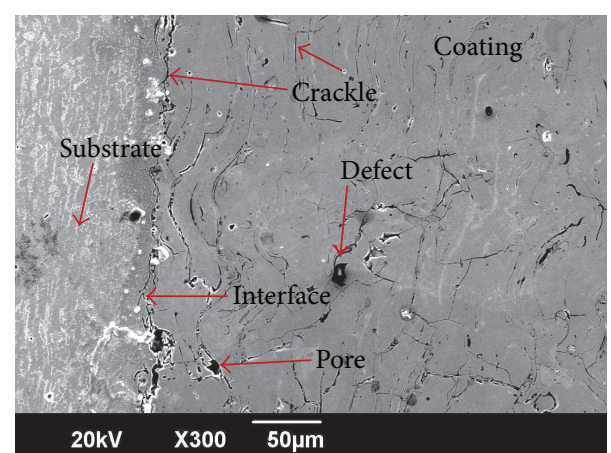

(b)

FIGURE 1: The optical and SEM images of the arc spraying coatings.

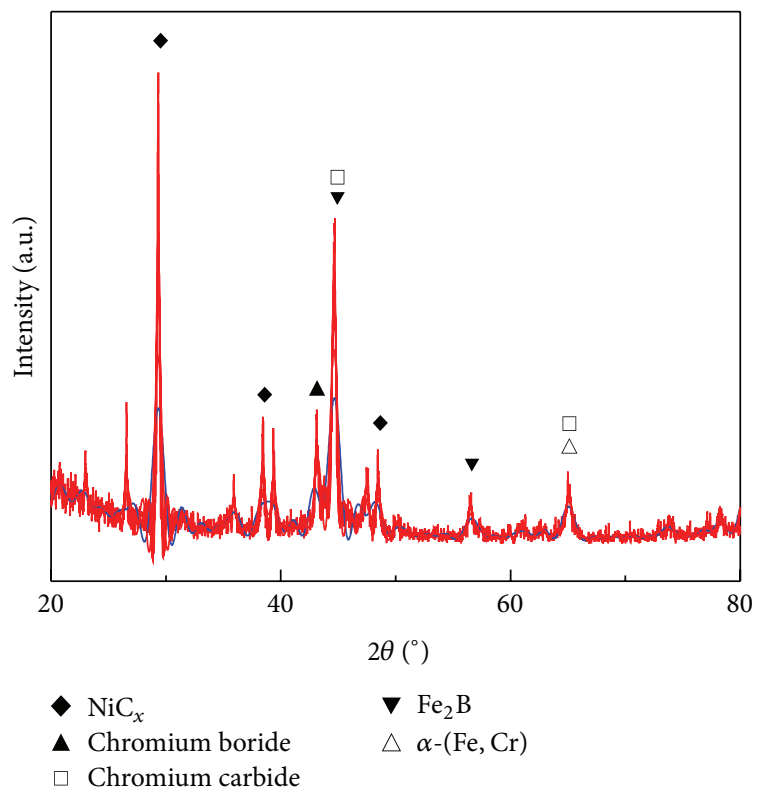

FIGURE 2: X-ray diffraction pattern of the coating after the plasma remelting. Red line: the original experimental data; blue line: curve fitting.

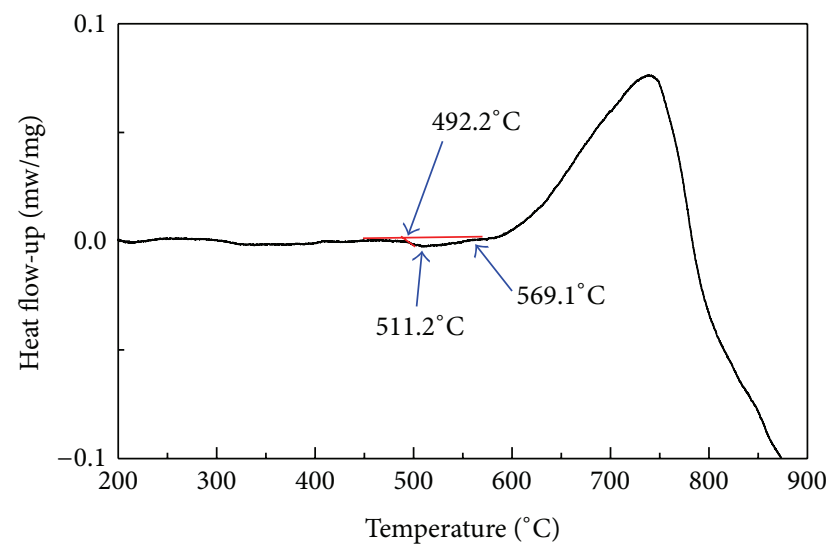

FIGURE 3: DSC curves of the coating after the plasma remelting.
The amorphous matrix and dendritic grains with different phases composed the micromixed eutectic structure: on the surface of remelted area, the small granular grains are formed due to the rapid solidification of the remelted layer. The high temperature gradient determines the directional solidified fine grain structure of the remelted layer. In the surface of the remelted area which possesses the maximum temperature gradient, no dendritic grains formed [11]. Compared with the dendrite layer of the remelted area, the numbers of cellular dendritic phases are greatly reduced and the microstructure becomes more diffused and refined, which are beneficial to the uniform distribution of the carbide and boride reinforcing ceramics.

Figure 5(a) illustrates the optical cross-sectional micrograph of the remelted coating, showing the dense and fine structure with no obvious cracks and pores. During the collision process between the droplet and substrate, the portion iron of the substrate diffused into the coating, and the chromium of the coating diffused into the substrate. In other words, on both sides of the interface, the distribution transitions of $\mathrm{Fe} / \mathrm{Cr}$ are obvious, and the diffusion is very uniform, this leading to the fact that the coating and the substrate form a metallurgical bonding. And the metallurgical bonding ensured that the coating has a high wear resistance and impact resistance.

Figure 6 is the microhardness gradient distribution of the coatings before and after remelting. As shown in Figure 6(b), the maximum hardness of the remelted coating achieves $1220 \mathrm{HV}_{0.3}$ which is higher than the arc spraying coating $\left(980 \mathrm{HV}_{0.3}\right)$; This is mainly due to the rapid condensation in the remelting process resulting in the droplets' refined, and a large number of nanocrystalline/amorphous structure's synthetic in the original position, as well as a lot of chromium boride and chromium carbide and other hard phases' precipitated and uniformly dispersed in the coating. In addition, plasma remelting reduced the voids and cracks in the coating. Figure 6(b) illustrates that the hardness of the top surface is higher than that of the middle and lower region of the remelting coating. This is mainly due to the faster cooling rate and being without element dilution in the top surface, leading to the formation of plenty of amorphous/nanocrystalline and homogeneous microstructures. 

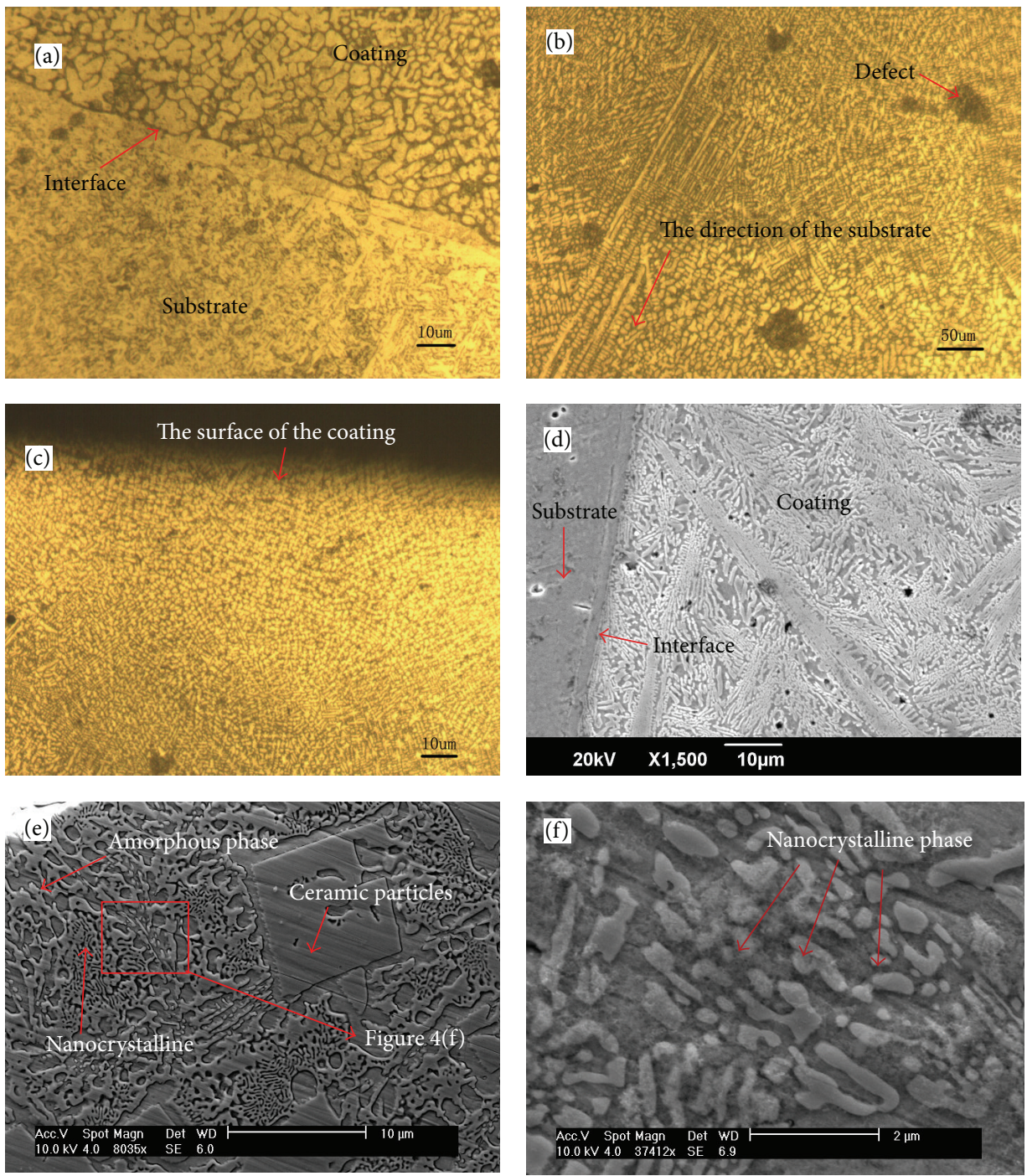

FIGURE 4: Images of the coatings after remelting: (a) the OM image of the interface of the coating and substrate; (b) the OM image of the center area of the coating; (c) the OM image of the top area of the coating; (d) the SEM image of the coating; (e) the upper region of the coating; (f) amorphous/nanocrystalline phase.

The microhardness of coating is suitable for the complex rules of composite materials (ROM) and is determined by both of the microhardness $(H)$ and the volume fraction $(V)$ of each phase [12]:

$$
H_{C}=H_{\alpha} V_{\alpha}+H_{\beta} V_{\beta} .
$$

In the formula, $H_{\alpha}$ and $H_{\beta}$ are the hardness of $\alpha$ phases and $\beta$ phases in the coating; $V_{\alpha}$ and $V_{\beta}$ are the volume percentage of $\alpha$ phases and $\beta$ phases in the coating.

From formula (1), microhardness of Fe-based amorphous composite coatings prepared by this experiment is determined by the amorphous and nanocrystalline grains in the coating.

By formula (1) also can be judged in the composite coatings the relationship between the hardness and the phase volume fraction is not linear. The maximum value of hardness is at the top region of the coating, and substrate/transition region is lower and was caused by the hierarchical microstructure of the coating. Because of in the remelting process, the cooling speed and the composition in the different area of the coating are both different, at the bottom of the coating, the composition deviated from the original composition influenced by the liquid alloy's melting and dilution; meanwhile the noncritical cooling rate of amorphous alloy becomes higher, resulting in the amorphous formation ability decreased. These changes on the composition and crystallization reflected in the organizational structure that is in different region of the coating have different micromorphology [13].

\section{Conclusions}

A kind of Fe-based amorphous/nanocrystalline composite coatings was prepared by arc spraying and remelted by a plasma remelting system. The hardness of the composite 


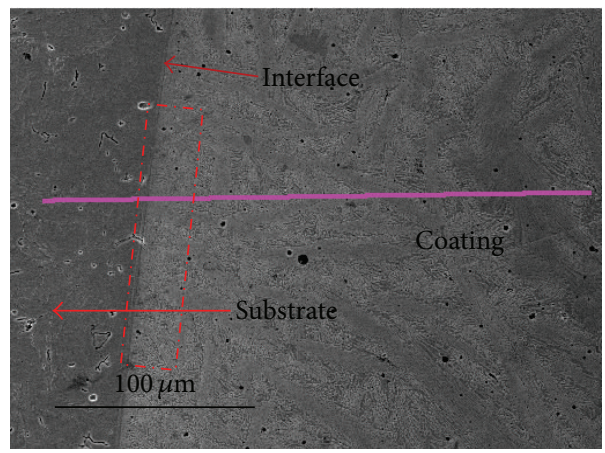

(a)

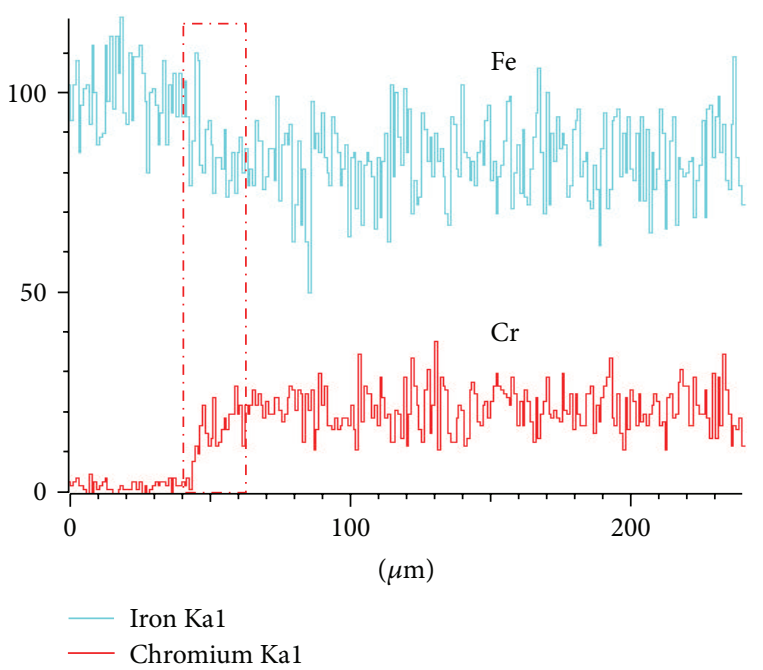

(b)

FIgURE 5: (a) The SEM image of the remelted coating; (b) the EDS analysis along the red line in (a).

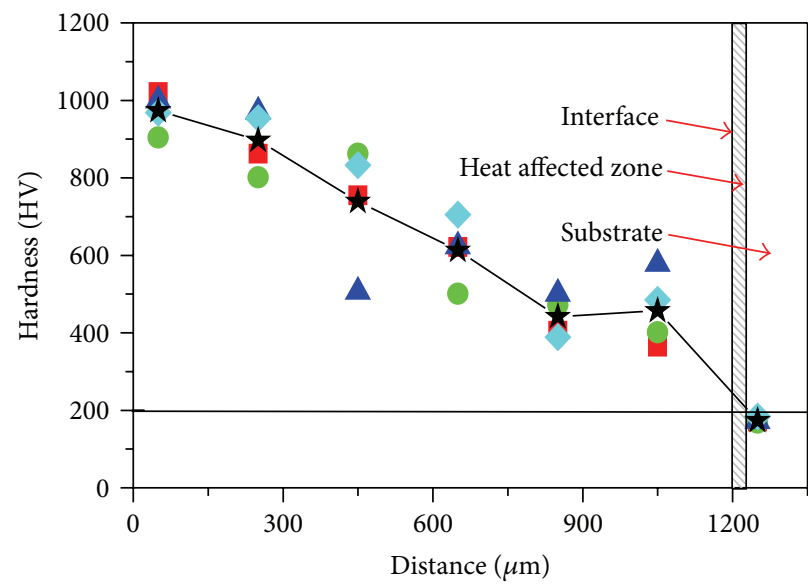

(a) Hardness gradient without remelting

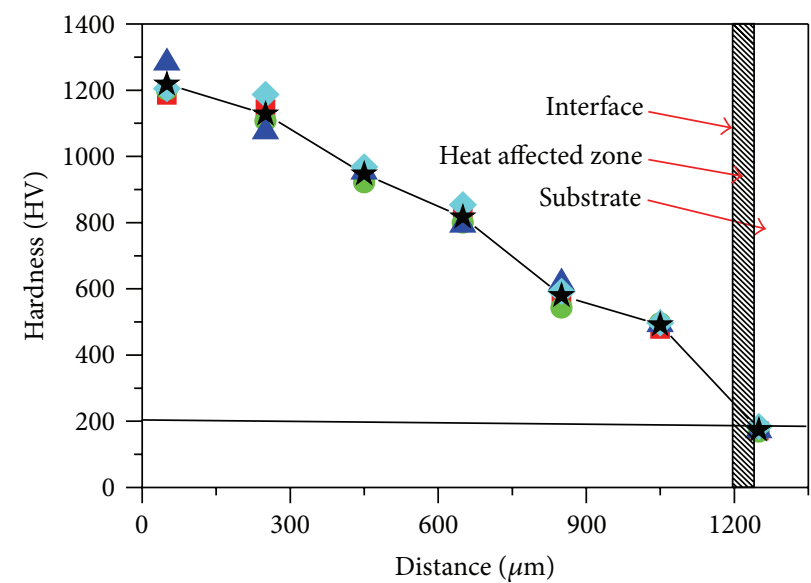

(b) Hardness gradient after remelting

FIGURE 6: The hardness curves of the arc spraying and remelted coatings.

coatings is significantly higher than that of the matrix, the maximum hardness reached $1220 \mathrm{HV}_{0.3}$, the coating and the substrate form a metallurgical bonding, and the structure of the coating is compact. Amorphous/nanocrystalline structure was synthesized in situ, and their synergistic action caused the coating to have good hardness characteristics, which have great potential applications in the field of antiwear and anticorrosion [14].

\section{Conflict of Interests}

The authors declared that they have no conflict of interests regarding this work.

\section{Acknowledgment}

This research was funded by the National Natural Science Foundation of China (11372110, 51101056).

\section{References}

[1] M. Yandouzi and B. Jodoin, "WC-based coating production by the pulsed gas dynamic spraying process: coatings and process analysis," in Proceedings of the International Thermal Spray Conference, pp. 219-224, 2009.

[2] M. Yan, "An experimental study of the remelting of an Fe-CCr-Si-B overlay with a microbeam plasma arc," Surface and Coatings Technology, vol. 99, no. 1-2, pp. 132-139, 1998.

[3] J. Cheng, X. Liang, B. Xu, and Y. Wu, "Microstructure and wear behavior of $\mathrm{Fe}-\mathrm{B}-\mathrm{Si}-\mathrm{Nb}-\mathrm{Cr}$ metallic glass coatings," Journal of Materials Science and Technology, vol. 25, no. 5, pp. 687-690, 2009.

[4] R. Q. Guo, C. Zhang, Q. Chen, Y. Yang, N. Li, and L. Liu, "Study of structure and corrosion resistance of Fe-based amorphous coatings prepared by HVAF and HVOF," Corrosion Science, vol. 53, no. 7, pp. 2351-2356, 2011.

[5] Y. Meijie, Study on High-Temperature Abrasion Resistant Coatings of Circulating Fluidized Bed Boiler, College of Mechanical 
and Electronic Engineering, Shandong University of Science and Technology, Qingdao, China, 2004 (Chinese).

[6] Y. Noda, A. Sato, S. Tobe, M. Hara, and T. Inaba, "Development of alternative method of blasting and ultra-high adhesive strength thermal spray coatings by vacuum arc treatment," Materials Transactions, vol. 50, no. 4, pp. 825-831, 2009.

[7] J.-J. Fang, Z.-X. Li, and Y.-W. Shi, "Microstructure and properties of $\mathrm{TiB}_{2}$-containing coatings prepared by arc spraying," Applied Surface Science, vol. 254, no. 13, pp. 3849-3858, 2008.

[8] R. Luding, R. Thorpe, and R. V. Hinckley, “The development of twin wire arc and HP/HVOF sprayed coatings for coal-fired steam generation boiler," Advanced Materials and Processes, vol. 168, no. 2, pp. 34-36, 2010.

[9] M. F. Cerqueira, J. A. Ferreira, and G. J. Adriaenssens, "Structural studies and influence of the structure on the electrical and optical properties of microcrystalline silicon thin films produced by RF sputtering," Thin Solid Films, vol. 370, no. 1-2, pp. 128-136, 2000.

[10] L. Liu, M. Sun, Q. Zhan, B. Liu, and C. L. Qiu, "Crystallization,mechanical and corrosion properties of $\mathrm{Zr}$ _Cu_Ni_Al_Nb bulk glassy alloys," Acta Physica Sinica, vol. 55, no. 4, pp. 19301935, 2006.

[11] Y. T. Wang, M. M. Yuan, J. K. Duan et al., "Hardness regulation of Fe-based amorphous composite coatings by laser remelting," Materials Science Forum, vol. 789, pp. 64-69, 2014.

[12] R. K. Goyal, A. N. Tiwari, and Y. S. Negi, "Microhardness of PEEK/ceramic micro- and nanocomposites: correlation with Halpin-Tsai model," Materials Science and Engineering A, vol. 491, no. 1-2, pp. 230-236, 2008.

[13] Q. Zhu, Z. Zou, S. Qu, and X. Wang, "Fabrication and microstructure of Fe-based amorphous composite coatings by laser cladding," China Welding (English Edition), vol. 17, no. 1, pp. 23-28, 2008.

[14] D.-B. Sun, Z.-S. Fan, H.-Y. Yu et al., "The research progress of amorphous nano-composite coating with high corrosion and wear resistance," Thermal Spray Technology, vol. 1, no. 2, pp. 1-6, 2009. 

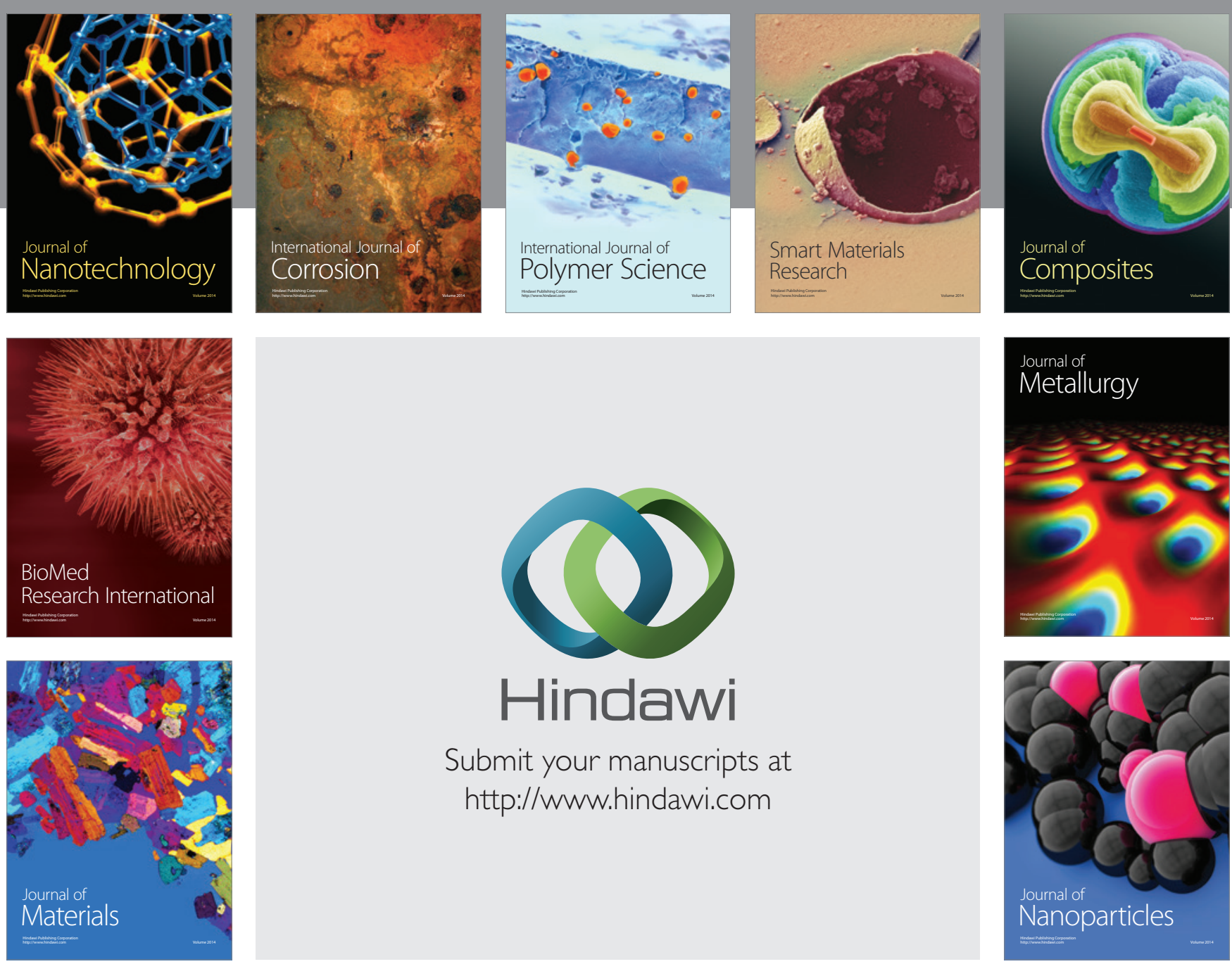

Submit your manuscripts at http://www.hindawi.com
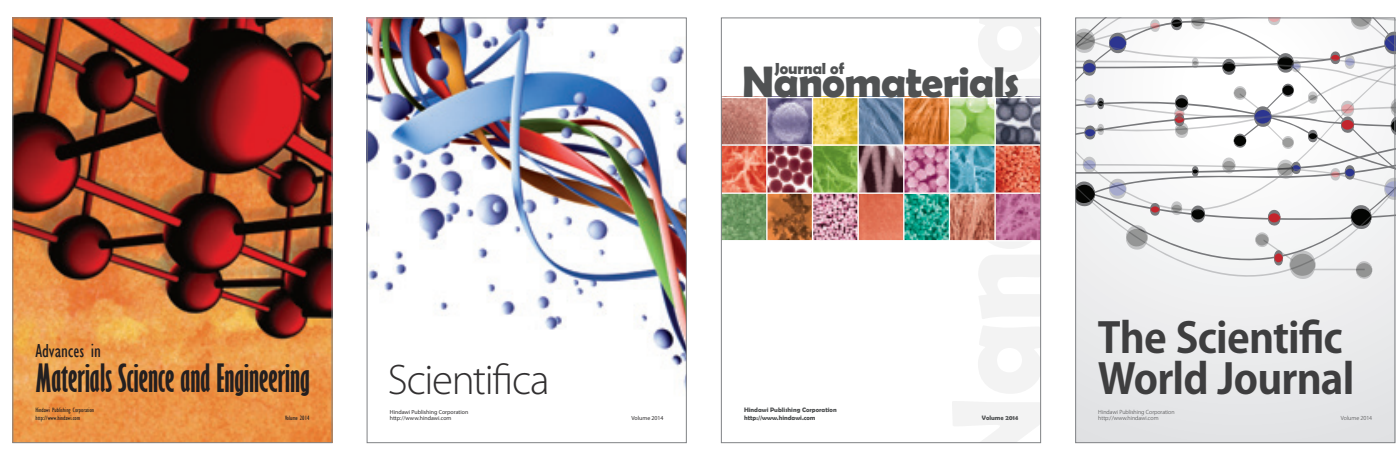

\section{The Scientific World Journal}
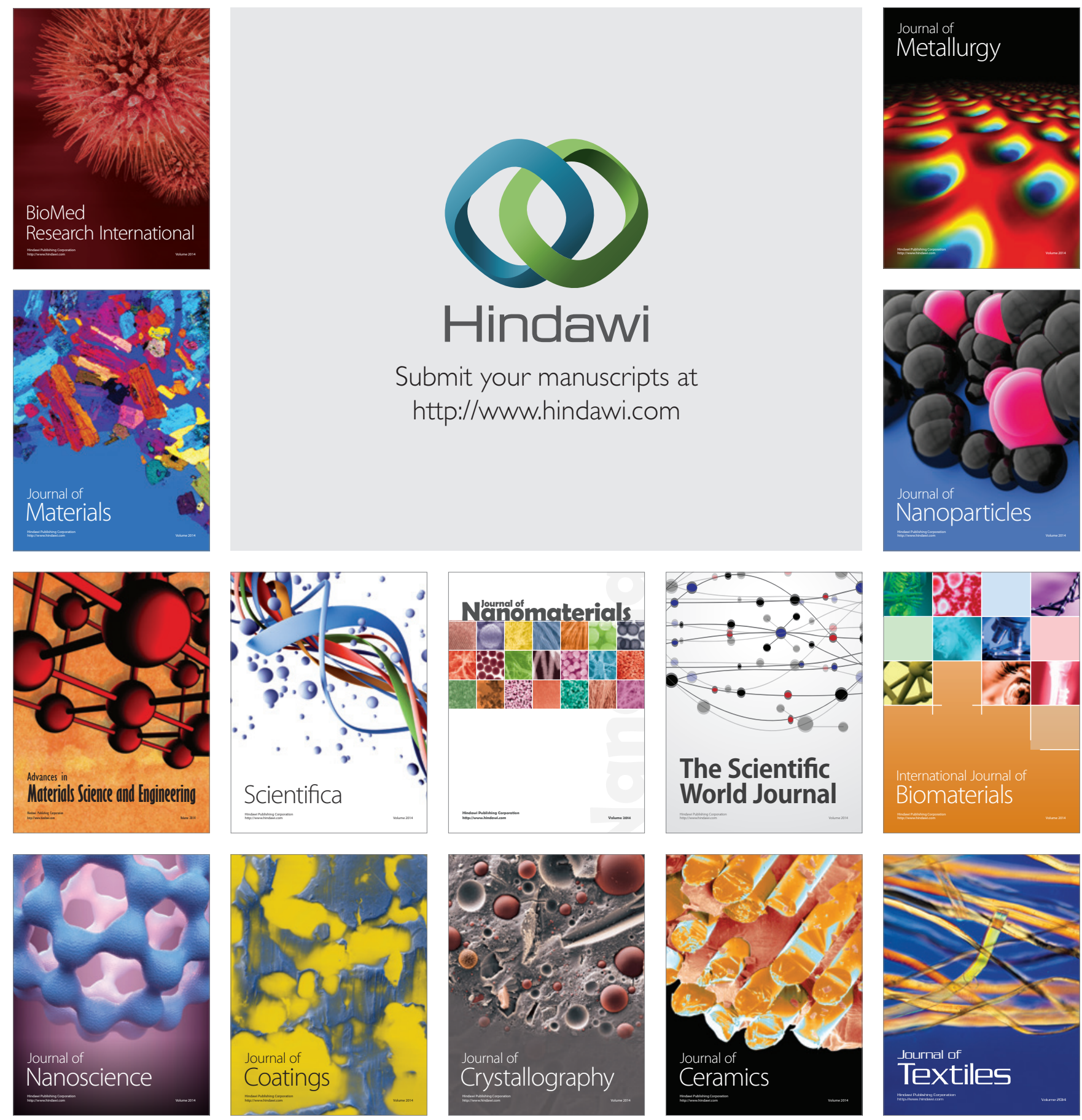